Article

\title{
Designing Assistive Devices for Sacred Palanquin Carriers: A Glocalization Community Design
}

\author{
Ming-Chyuan $\mathrm{Ho}^{1}$ and Ying-Hsun Chen ${ }^{2, *}$ \\ 1 Department \& Graduate School of Industrial Design, National Yunlin University of Science and Technology, \\ Douliou 64002, Taiwan; homc@yuntech.edu.tw \\ 2 Graduate School of Design, National Yunlin University of Science and Technology, Douliou 64002, Taiwan \\ * Correspondence: joan17070@gmail.com
}

Received: 31 March 2020; Accepted: 12 April 2020; Published: 16 April 2020

check for updates

\begin{abstract}
New knowledge and technology brought about by globalization can be applied to revitalize local cultures in innovative ways. It can start with glocalization community design to sustain unique traditional events so as to energize the community. The paper proposes a study on designing assistive devices for exclusive palanquin carriers for a local religious event. Field investigation, questionnaire survey, and in-depth interviews were adopted to design appropriate assistive devices for palanquin carriers. This design used shoulder protectors to reduce the pain of the palanquin carriers. It is recommended that the palanquin carriers wear a shoulder protective vest with a protector applied to each shoulder to share the weight of the palanquin to maintain a good physical condition so as to facilitate the completion of the event. The task is to develop a protective vest that the palanquin carriers love to wear and will become the focus of attention in the detouring. The designed protective vest could attract more young people to participate in the event, that is how the aging problem could be solved. It is the first but important step to resolve the aging crisis of the event.
\end{abstract}

Keywords: community design; event; globalization; glocalization; local culture; religion; sustainability

\section{Introduction}

There are few papers on Taiwan's sacred palanquin. The only paper currently available is a master thesis of the Graduate School of Architecture and Historic Preservation, Taipei National University of the Arts in 2008. The author is Bo-Hsun Yao and the title is "The Ambrosial Palankeen of Taiwan". Palankeen is an alternative spelling of palanquin. Palanquin (in India and the East) is a covered litter for one passenger, consisting of a large box carried on two horizontal poles by four or six carriers. "Ambrosial" means suitable for God. "Ambrosial palankeen" is synonymous with the sacred palanquin. This master thesis, as its abstract said, "focuses on three dimensions of ambrosial palankeen: As traditional artwork, as architecture, and as a medium of religious beliefs." It is "an attempt to demonstrate the history and development of Taiwan's ambrosial palankeen culture with an analysis of the palanquin's spatial structure and features." [1]. The focus of this master thesis is the history of Taiwan's sacred palanquin. With different intentions, this paper focuses on the future of Taiwanese sacred palanquin, including its crisis and resolution, and pays special attention to the impact of the certain detour event of sacred palanquins on community development.

The paper begins with a literature review to discuss the suitable way to deal with the globalization and recommend the strategy of local-oriented glocalization. It can start with community design to sustain unique traditional events so as to energize the community. The paper presents a research study on designing assistive devices for palanquin carriers for a local religious event. Field investigation, questionnaire survey, and in-depth interviews are adopted to design appropriate assistive devices for palanquin carriers. The protective vest, which involves young people in designing, will surely attract 
more young people to participate in the event, the aging problem is expected to be solved. It is only the first but important step to resolve the aging crisis of the event.

\section{Literature Review}

\subsection{Multi-Aspects of Globalization}

Superficially, globalization is just a rapid economic and financial expansion because its manifestations are frequent trade developments and close financial exchanges across national borders over long distances. According to the definition of the World Health Organization (WHO), "Globalization, or the increased interconnectedness and interdependence of peoples and countries, is generally understood to include two interrelated elements: The opening of international borders to increasingly fast flows of goods, services, finance, people and ideas, and the changes in institutions and policies at national and international levels that facilitate or promote such flows." [2].

It should be clarified that globalization is not merely the global commerce, but also contains many other essential aspects such as politics, military, technology, geography, ecology, society, culture, etc. For Malcolm Waters, globalization is considered to be a social process in which geographical barriers on economic, political, social, and cultural arrangements are gradually vanishing, and people are becoming more alert and taking corresponding actions. Waters sees globalization as a process instead of an end. He highlights the impact of globalization on culture as well as conscious response [3] (p. 5).

Anthony Giddens had already indicated that local transformation is a part of globalization. He said, "Globalization can [ ... ] be defined as the intensification of worldwide social relations which link distant localities in such a way that local happenings are shaped by events occurring many miles away and vice-versa. This is a dialectical process because such local happenings may move in an obverse direction from the very distanced relations that shape them. Local transformation is as much a part of globalization as the lateral extension of social connections across time and space." [4] (p. 64).

Globalization has made relations around the world more and more closely connected, which makes the link between local and global inseparable. Actually, the local people should not be reluctantly adapted to globalization, but they should respond confidently in a matching way.

Thomas Friedman claimed that globalization is not simply a trend or fad but an international system to replace the old Cold War system, which is built around three balances. The first is the traditional balance between nation-states. The second balance in the globalization system is between a nation-state and global markets. The third is the newest balance between individuals and nation-states. He explicated the third balance that "globalization has brought down many of the walls that limited the movement and reach of people, and because it has simultaneously wired the world into networks, it gives more power to individuals to influence both markets and nation-states than at any time in history. Individuals can increasingly act on the world stage directly - unmediated by a state." As a result, individuals have been "super-empowered" [5]. Thanks to affordable ICT equipment, YouTube stars become an outstanding example of how individuals can depend on their own knowledge and abilities to act as strong competitors against traditional celebrities.

\subsection{Two Kinds of Glocalization}

As stated by Roland Robertson, glocalization, combining globalization and localization into one word, is a term invented by Japanese economists to explain their global marketing strategy. He said, "The very formulation, apparently in Japan, of a term such as glocalize (from dochakuka, roughly meaning 'global localization') is perhaps the best example of this. Glocalize is a term which was developed in particular reference to marketing issues, as Japan became more concerned with and successful in the global economy, against the background, as we have seen, of much experience with the general problem of the relationship between the universal and the particular." [6] (pp. 173-174).

In marketing, glocalization refers to expanding the global market by improving products with the adaptation of local culture. For example, the main population of Indonesia are Muslims, who believe 
that pigs are dirty and refuse to eat pork. Accordingly, all McDonald's restaurants in Indonesia have adopted to use fish instead of pork to meet local dietary needs. This kind of glocalization strategy is conceived from the viewpoint of multinational companies for promoting their global business. The purpose of taking care of local culture is just to expand the global occupation.

Local-oriented glocalization, which is rooted in local cultural practices, possibly will be wholly different. The progressive knowledge and advanced technology brought about by globalization can be applied to revitalize local cultures in innovative ways so as to strike a balance between the utmost realm of progress and the maintenance of traditions to ensure a better prospect for all. Only at such kind of local cultural concerns can we understand why John Tomlinson asserted "Globalization lies at the heart of modern culture, cultural practices lie at the heart of globalization." [7] (p. 1).

\subsection{Revitalizing Cultural Practices with Community Design}

How to implement local-oriented glocalization if we are sure it is worth facilitating? It can start with community design to revive the local cultural practices in order to vitalize the community. Yamazaki Ryō pointed out: "The unique rules and customs that a community has maintained, along with the networks and sense of trust built up through such things as festivals and traditional culture, can enrich the whole community and make it a more vibrant place" [8]. In other words, sustaining unique traditional events of the community is helpful to build a close personal network that trusts one another and energizes the community.

As a community designer, Yamazaki Ryō founded Studio-L in 2005 to offer innovative solutions for local problems by inspiring and leading the local communities. According to Yamazaki, community design involves supporting residents themselves to address the problems facing their community, making use of their interpersonal connections and their own ideas about what can be done to reinvigorate the place where they live. Yamazaki advocates the importance of community design, which he defined as the empowerment of the locals through design to make them happy. The goal of his projects is to revitalize the local area. He is committed to understanding the dynamic at play in community revival [8].

\section{Research Motivation}

\subsection{Background}

Inspired by Yamazaki Ryō, the paper attempts to implement local-oriented glocalization in light of the idea of community design. The community design implemented is focused on the detour event of "Old Second Mazu Return to Her Mother's Home" in Xitun District, Taichung City, Taiwan. Ying-Hsun Chen found that this religious event is vital to the local culture of Xitun District during investigating the historical background of the development of the Zhang Liao clan in Taichung City in 2018 when she wrote a book entitled "Ancestral Halls of the Zhang Liao clan and the Hakka Historical Memory of Xitun District, Taichung City" which was commissioned by the Council for Hakka Affairs of Taichung City Government.

The detour event is held once every three years, and the most recent one was 28 and 29 April 2018. She personally recorded the whole process of this detour with her video camcorder and interviewed the seniors of the Zhang Liao clan several times as well. Since both two palanquins used in the detour can be disassembled and reassembled, she was able to photograph their detailed structure with permission. According to the Chinese characters carved on the first exclusive palanquin for "Second Mazu", it was made in the fifth month of the lunar calendar, the seventh year of the Jiaqing Emperor (1802). It can be inferred that the first detour was in the second year after completing this palanquin, which is 1803. It has a history of more than 216 years.

The detour event was originally held once a year, however, the Second Mazu seemed unwilling to return to the Wanhe Temple too early. It rained on the return trip, as if the Second Mazu was crying. 
Devotees did not want to see Mazu suffer every year, so the event was changed into every three years. The stay was also shortened from three days to two days [9] (p. 275).

The event of "Second Mazu Return Home" is organized by the Mazu Association called "Dan Qing Ji" which was founded by the members of Zhang Liao clan who are firmly convinced that the soul of their female ancestor was attached on "Second Mazu", the avatar of the Mazu, built by the Wanhe Temple in Nantun District, Taichung City. Hence, they called her "Aunt Ancestor", and decided to pick her up regularly from Wanhe Temple to return to their ancestral hall in Xitun at the event. Therefore, it is an exclusive palanquin, which consists of a seat with a cover that is carried by eight people with two long poles as a means of transportation for the goddess during the pilgrimage, see Figure 1. It was made for her, and the carrier team is formed with volunteers from the Zhang Liao clan. All the expenses of the event are entirely covered generously by the Zhang Liao clan. Apparently, "Second Mazu Return Home" is a clan-led event.

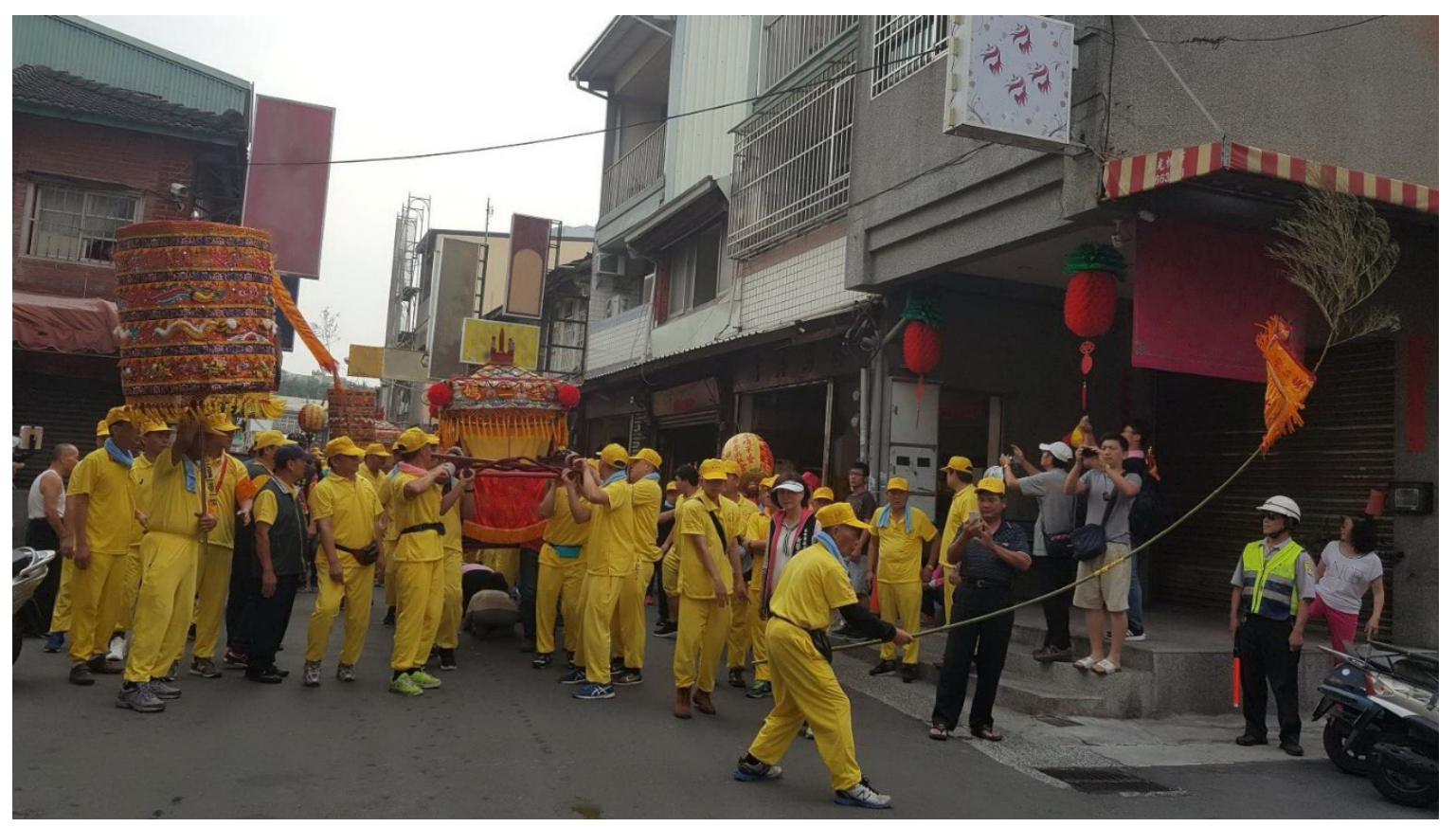

Figure 1. Two antique palanquins for "Old Second Mazu" and "Sacred Second Mazu" were paraded during the event of "Old Second Mazu Return to Her Mother's Home" in 2018.

During the Japanese colonial period, as there were more and more devotees of the Second Mazu in Xitun, the circle of believers was gradually expanding, the original single route could no longer satisfy the wishes of all the believers in Xitun. Therefore, an avatar of Second Mazu known as "Sacred Second Mazu" was added by the Wanhe Temple in order to increase an auxiliary route. To avoid confusion, the original Second Mazu statue entitled the "Old Second Mazu". With the intention of making another exclusive palanquin for "Sacred Second Mazu", the devotees in Xitun were eager to donate. Another carrier team to carry "Sacred Second Mazu" was organized voluntarily by the residents of Xitun. The clan-led event becomes the event of Xitun after increased participation of Xitun residents.

Even though the scale is far less than that of Mazu Pilgrimage held by Zhenlan Temple in Dajia District, Taichung City, which is the most popular 300-kilometer, nine-day detour in Taiwan, it cannot be ignored that "Old Second Mazu Return to Her Mother's Home" generates strong cohesion for the Zhang Liao Clan as well as the Xitun community.

Two antique palanquins for "Old Second Mazu" and "Sacred Second Mazu", which are very rare today, have been properly kept by the Zhang Liao clan. The former was made in the Qing Dynasty and the latter was made during the Japanese colonial period. According to the Chinese characters carved 
on the palanquins, the former was made in the fifth month of the lunar calendar, the seventh year of the Jiaqing Emperor (1802), the latter was made in the 13th year of Taisho (1924). As of 2020, they have a history of 218 years and 96 years, respectively. The mission of these two antique palanquins is to carry the goddess statue with her avatar to visit her relatives. The sacred palanquin is not only a means of transportation for the goddess, but also a sacred artifact. Devotees participating in the pilgrimages will pass under the palanquin, some even carry the palanquin to access the sacred space for receiving divine grace.

The weight of the palanquin of Old Second Mazu plus the statue, ornaments, and poles is $133.15 \mathrm{~kg}$. It is distributed to eight palanquin carriers. One person bears the load of $16.64 \mathrm{~kg}$ when not in motion. The weight of the palanquin of Sacred Second Mazu is lighter. After adding the statue, ornaments, and poles, its weight is $113.15 \mathrm{~kg}$. It is distributed to eight palanquin carriers. One person bears the load of $14.14 \mathrm{~kg}$ when not in motion. The aging of Taiwan society is a potential crisis to the continuousness of pilgrimage. Definitely, the people usually involved in the pilgrimages will age and become less and less in number. Sooner or later, no one will be able to carry the heavy sacred palanquin, which plays an important role in the pilgrimage. If the traditional way to carry the palanquin by people is not changed, then the palanquin carriers will have to withdraw soon because they are elderly or injured. Finally, the important traditional celebration of the pilgrimage will disappear.

\subsection{Solving the Unsustainable Crisis of the Event with Community Design}

The event of "Old Second Mazu Return to Her Mother's Home" has been going on for a long time, however, it is only held once every three years, and the preparations for this event are too casual. In addition, the amateur palanquin carriers lack training, and they are gradually aging. This kind of unsustainable crisis should be addressed. The problem can be expected to be resolved through community design.

According to a questionnaire survey of 26 amateur palanquin carriers who are responsible for carrying the palanquin for Old Second Mazu and Sacred Second Mazu, their average age is 35.68 years old. According to oral interviews with the captain and former captain of the palanquin-carrying team for Old Second Mazu, their estimates were the same: The average age of palanquin carriers was forty years old. They all claimed that they became palanquin carriers were they were 16 or 17 years old. There is only one person under 20 years old, only $3.8 \%$ of the 26 palanquin carriers. It shows that the percentage of young members in the palanquin-carrying team is low. Most carriers are 35-45 years old, with a total of 10 people, accounting for $38.4 \%$ of the total number. It shows that the ageing of the palanquin-carrying team will be a crisis for maintaining the palanquin-carrying customs.

As mentioned above, Yamazaki's community design philosophy is to guide residents to solve their own problems and use their relationships and ideas to invigorate their communities. Since Chen Ying-Hsun is not a member of the Zhang Liao clan, it is not proper to interfere directly with the foremost event organized by the clan. What can be done to guide them to face the crisis and solve it properly?

The solution that came to our mind was to propose a study on designing assistive devices for exclusive palanquin carriers for the detour event of "Old Second Mazu Return to Her Mother's Home" in Xitun District, Taichung City, Taiwan, and a request for cooperation was raised. Then, opportunities were created to meet the team of palanquin carriers and discuss the difficulties they encountered while carrying the palanquin. To develop assistive devices that the palanquin carriers are willing to use is just one of the solutions to the crisis. In the process of investigation and design, the palanquin carriers felt that their feelings and needs were valued. They were excited to wear the protective vest which they were involved in designing, and eager to put the protective vest on during the next detour. Hence, they were proud of becoming the focus of attention when they were detouring. The designed protective vest could attract more young people to join the palanquin carrier team and participle in the detour event, that is how the aging problem is expected to be solved. When young people are enthusiastically engaged in the detour activities, there will be enough young manpower to participate vigorously in 
the planning of the activity. Then, the aging and casual crisis will be solved. If the strategy is workable, sooner or later, the intangible spiritual achievements of community design will be felt. However, we need to start with the visible design, even if this is only the first step. The paper can only report on the research results of this first step below. The follow-up effect remains to be observed.

\section{Research Methodology}

\subsection{Research Procedure}

The paper explored the operation of the palanquin carriers from the point of view of design for the user. Through field investigation and feedback from the palanquin carriers, the results were analyzed, and the design and proposal of the protector for the use of the palanquin carrier were proposed. The research procedure of this paper is shown in Figure 2.

The research procedure is as follows:

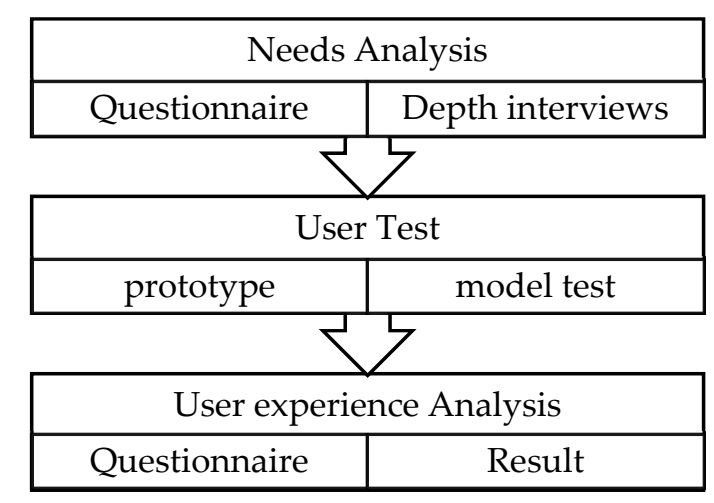

Figure 2. Research procedure.

The purpose of this study is to solve the discomfort caused by musculoskeletal pain during the process of carrying a palanquin. By exploring the qualities users desire and their approaches to meet these qualities, designers may form a basic understanding of the design problem at hand. We believe this absolutely necessary for creating design solutions appropriate for the user. This study used semi-structured interviews, the teams of palanquin carriers were investigated and it was understood that they value the cultural heritage and are not willing to use the modified wheel palanquin to carry out the pilgrimage activities. In-depth expert interviews were carried out to summarize the points for field investigation. The members of the carrier team for Old Second Mazu's palanquin in Xitun District, Taichung City, were taken as the interviewees.

\subsection{Design Process of Protective Vest}

The purpose of design is to lighten the pain or discomfort for the palanquin carriers. The process of design was divided into three stages: The first stage is the preliminary improvement design, the second stage is the experience sketch design, and the third stage is the advanced improvement design (see Figure 3). 


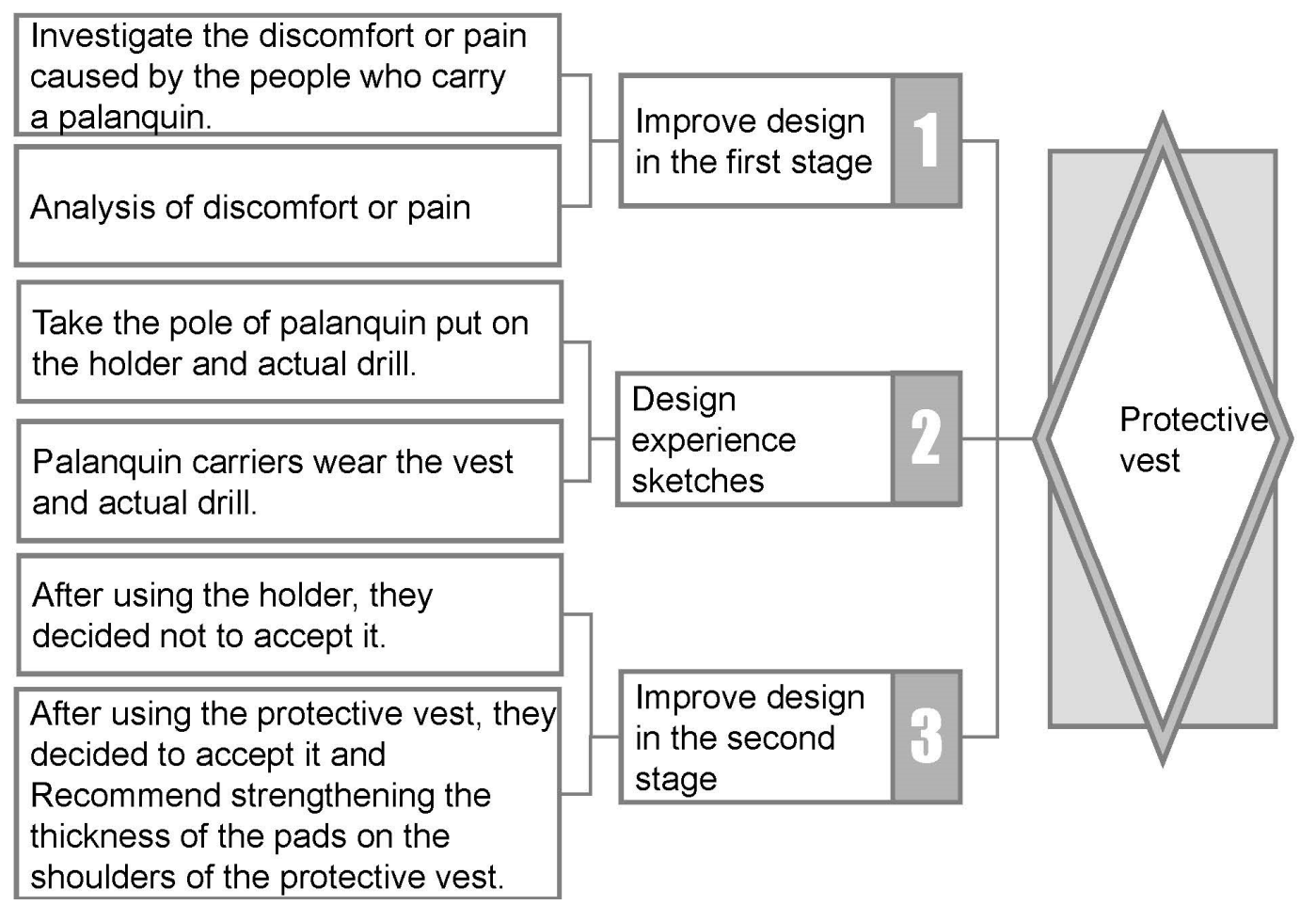

Figure 3. Design process of a protective vest.

The survey was conducted with purposive sampling. Purposive sampling is a common nonprobability method. The researcher selects the sample based on judgment. The palanquin carriers for Old Second Mazu at the Zhangliao Ancestral Hall in Xitun District, Taichung City, were taken as the respondents of the questionnaire.

This is usually an extension of convenience sampling. For example, a researcher may decide to draw the entire sample from one "representative" city, even though the population includes all cities.

The researcher selects the sample that is most suitable for the purpose of the research based on personal subjective judgment. Judgment sampling is the type of sampling accepted under special circumstances.

Purposive sampling is most effective when only a limited number of individuals possess the trait that a researcher is interested in.

This study takes this family as an example of investigation because the Old Second Mazu pilgrimage activities undertaken by the Zhangliao family are among the few festivals in Taichung with a high degree of urbanization that can last for more than 200 years.

In this case, purposive sampling is the only viable option for obtaining information from the Zhangliao family. This family also provides major human support for the event.

Almost all of the palanquin carriers for Old Second Mazu at the Zhangliao Ancestral Hall in Xitun District, Taichung City, come from the Zhangliao family.

This study hopes to help the local cultural activities to be sustainable. Therefore, we will help the palanquin carriers for Old Second Mazu at the Zhangliao Ancestral Hall in Xitun District, Taichung City, who carry out trips around the Xitun District every three years to design protective gear so that they can alleviate discomfort and continue to serve Old Second Mazu.

Questionnaires were distributed on 4 August 2019. The survey method was to arrange the palanquin carriers and the interviewers to go to the scene, the questionnaires were distributed to the respondents related to the sacred palanquin. The questionnaires were filled in face-to-face interviews and collected on site. The total number of questionnaires distributed was 30 , and the number of valid questionnaires was 26 . The invalid questionnaires and the questionnaires from the respondents who were members of the team of palanquin organization but did not actually participate in the 
work of carrying the palanquin were excluded. The total rate of effective questionnaires was $86 \%$. The investigation was to get the order of the items that should be prioritized when designing so that the protector designed for the palanquin carriers is more convenient, comfortable, and safe.

The content of the questionnaire is divided into two parts. The first part is the "Basic Data Survey" of the respondents. There are nine questions in total, mainly for the user's attribute and experience survey, including sex, age, seniority, and purpose.

The second part is "Demand Consideration of God's Palanquin Users", mainly based on the survey of the user's perception of the design and space of the god's palanquin, with a total of seven questions. The questionnaire design adopted the grade method, and the research topics were classified according to attitudes or opinions, and divided into three grades of no consideration, secondary consideration, and priority consideration.

For the questionnaire reliability and validity analysis, SPSS 23rd edition was used to analyze the survey results. The overall reliability value (Cronbach's $\alpha$ ) was 0.791 . Among them: The reliability values of the two constructs of "The same height of the palanquin carriers facilitates the carrying of the palanquin" and "Have sufficient physical training beforehand" were both higher than 0.78 [upper and middle reliability]. The validity values of all the questions in this questionnaire were higher than 0.7 , which shows that the measurement questions of this questionnaire can fully and effectively reflect the feelings of the palanquin carriers investigated. The first part is the "Basic Data Survey" of the respondents. After the two managers who have never participated in the palanquin carrying were deducted, and the invalid questionnaires were removed, the average age of the 26 palanquin carriers was 38.5 years old. By employing the questionnaire, we found that of 26 people who felt pain in the palanquin carrying, 24 felt pain in their shoulders, accounting for $92 \%$, and the other two felt pains in both the shoulders and wrist, and the shoulders and waist. Based on the statistical results, this study used the shoulder as the direction for the design of the protectors.

\subsection{In-Depth Interview}

In this paper, nine relevant interviewees were selected for further in-depth interviews. The backgrounds of the interviewees were a physician, a massage therapist, a palanquin-carrying team, a professor of design and a god palanquin operator. According to the interview content, the principles of designing palanquin protection gear were sorted out. According to the content of the interview, the principles of designing the protective equipment for carrying a palanquin were sorted out (see Table 1).

Nine respondents were selected for the interview, including two medical professionals for trauma, one for ergonomic research, one for sacred palanquin making, and five senior palanquin carriers. After sorting out the analysis based on the interview content, the recommendations the protector design for palanquin carriers are as follows:

- The height of the palanquin carriers is the same.

- The pace of the palanquin carriers is the same.

- Increase the load-bearing area of the carrier.

- Reduce the pressure on the unit bearing area.

- Share the power equally on both shoulders.

- The binding method of the palanquin is related to the average load of each palanquin carrier. 
Table 1. List of in-depth interviews.

\begin{tabular}{|c|c|c|c|}
\hline Interviewee Code & Interviewee Role & Interview Style/Time & Qualifications \\
\hline A. & Physician & $\begin{array}{l}\text { Interview and record/ } \\
1 \text { August } 2019\end{array}$ & $\begin{array}{c}\text { He has been a physician in his own } \\
\text { clinic for decades and is over } 80 \\
\text { years old. }\end{array}$ \\
\hline B. & Massage therapist & $\begin{array}{l}\text { Interview and record/ } \\
11 \text { August } 2019\end{array}$ & $\begin{array}{l}\text { He has } 20 \text { years of experience in } \\
\text { massage therapy, including } 10 \text { years } \\
\text { as a massage therapist in a Chinese } \\
\text { hospital, and } 10 \text { years in his own } \\
\text { massage workshop. }\end{array}$ \\
\hline C. & Professor of design & $\begin{array}{l}\text { Interview and record/ } \\
19 \text { October } 2019\end{array}$ & Expertise in ergonomics \\
\hline D. & $\begin{array}{c}\text { Leader of a } \\
\text { palanquin-carrying team }\end{array}$ & $\begin{array}{l}\text { Interview and record/ } \\
4 \text { August } 2019\end{array}$ & $\begin{array}{l}\text { Palanquin carrying experience for } \\
\text { more than } 20 \text { years }\end{array}$ \\
\hline E. & $\begin{array}{c}\text { Member of a } \\
\text { palanquin-carrying team }\end{array}$ & $\begin{array}{l}\text { Interview and record/ } \\
4 \text { August } 2019\end{array}$ & $\begin{array}{l}\text { Palanquin carrying experience for } \\
\text { more than six years }\end{array}$ \\
\hline F. & $\begin{array}{c}\text { Member of a } \\
\text { palanquin-carrying team }\end{array}$ & $\begin{array}{l}\text { Interview and record/ } \\
4 \text { August } 2019\end{array}$ & $\begin{array}{l}\text { Palanquin carrying experience for } \\
\text { more than six years }\end{array}$ \\
\hline G. & $\begin{array}{c}\text { Member of a } \\
\text { palanquin-carrying team }\end{array}$ & $\begin{array}{l}\text { Interview and record/ } \\
4 \text { August } 2019\end{array}$ & $\begin{array}{l}\text { Palanquin carrying experience for } \\
\text { more than six years }\end{array}$ \\
\hline H. & $\begin{array}{c}\text { Member of a } \\
\text { palanquin-carrying team }\end{array}$ & $\begin{array}{l}\text { Interview and record/ } \\
4 \text { August } 2019\end{array}$ & $\begin{array}{l}\text { Palanquin carrying experience for } \\
\text { more than six years }\end{array}$ \\
\hline I. & God palanquin operator & $\begin{array}{l}\text { Interview and record/ } \\
27 \text { November } 2019\end{array}$ & $\begin{array}{l}\text { Inherited the technique of making } \\
\text { palanquin from the family with } \\
\text { more than } 20 \text { years of experience. }\end{array}$ \\
\hline
\end{tabular}

\section{User Test}

The purpose of this study is to solve the discomfort caused by musculoskeletal pain during the process of bearing a palanquin.

Drawing output of pole holder on 18 December 2019, see Figures 4-6.

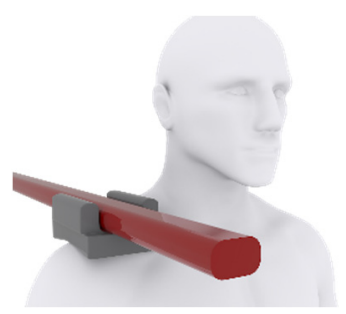

Figure 4. Simulation of pole holder.

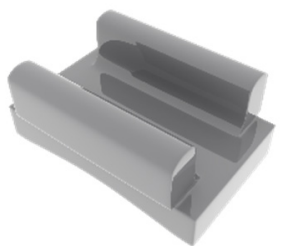

Figure 5. 3D illustration of pole holder. 


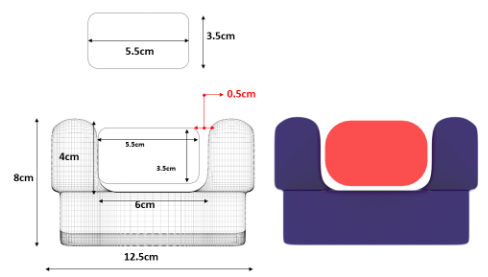

Figure 6. Size of pole holder.

On 28 December 2019, the palanquin-carrying team was tested to carry the palanquin fixture, and the user's opinions were recorded, see Figures 7-10.

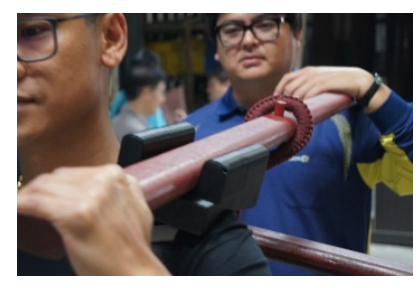

Figure 7. Testing pole holder.

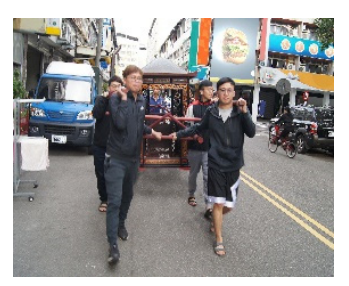

Figure 8. Testing on the street.

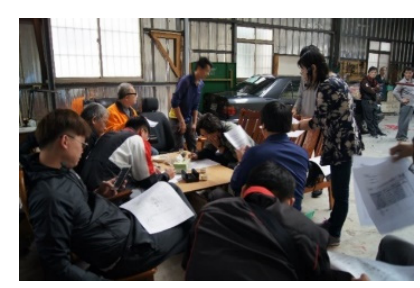

Figure 9. Fill out the use comments after the field test of the pole holder.

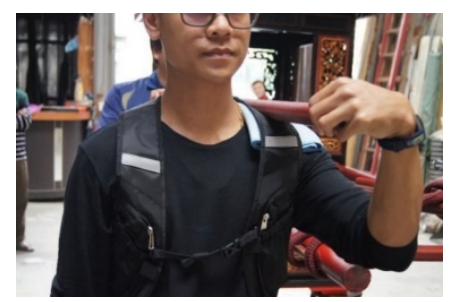

Figure 10. Design ideas for choosing protective vest after field test.

In the research, the finished product of the experience sketch on 28 December 2019 will be a test model, discussed with the site users, and finally re-correction data will be obtained to perform design modification actions.

After counting the data gathered from nine people, the shoulder is the most painful part that everyone thinks. 
Finally, the three aspects of the data were verified with each other, and the objective results of the design of the protective vest were summarized, and the third stage of correction was made to make the protective vest.

\section{Research Results}

After the palanquin for Old Second Mazu was measured, its weight of $133.15 \mathrm{~kg}$ was known. It was distributed to eight palanquin carriers. When not in motion, one person bears the load of $16.64 \mathrm{~kg}$.

The research provides a user design mode. At first, the content of the in-depth interview was summarized, and then the design sketch was drawn to allow the users to understand the feasibility of using the protective devices. It consists of a box that is carried by eight people with two long poles.

Wearing a protective shoulder device, the members of the Clan of Liao Lie-Mei adhered to the custom of regular pilgrimage, and they tried their best to preserve the disassembled palanquins for the goddess. One of the main discomforts is on the shoulder after carrying the palanquin. It may cause injury, such as shoulder dislocation, wearing a protective device, particularly near their shoulders, can help protect palanquin carriers from shoulder dislocation.

We designed the pole holder and vest for palanquin carriers. After the palanquin-carrying fixture was tested with the three-D output model designed by the sketch, the users refused to use it.

They have a high degree of acceptance for protective vests and are willing to wear it. They put forward suggestions for thickening shoulder pads. Based on the user design principles, the final conclusion of the research is the appropriate improvement for the design of protective vests, so that the palanquin carriers can get substantial protection during the process of pilgrimage (see Figures 11 and 12).

The arrows show the recommended modification positions for the shoulder protector. The protective shoulder for a palanquin carrier can support the back, neck, and braces (see Figures 13 and 14).

The revised specifications of the protective vest are shown below:

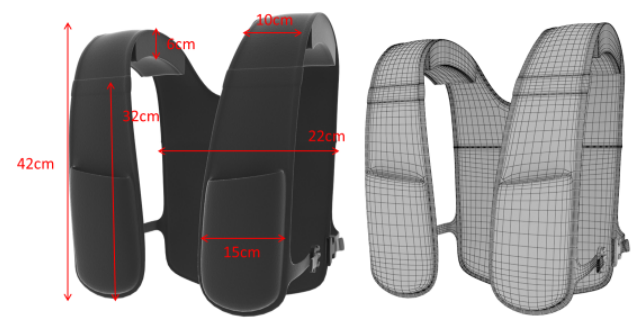

Figure 11. Front of the protective vest.

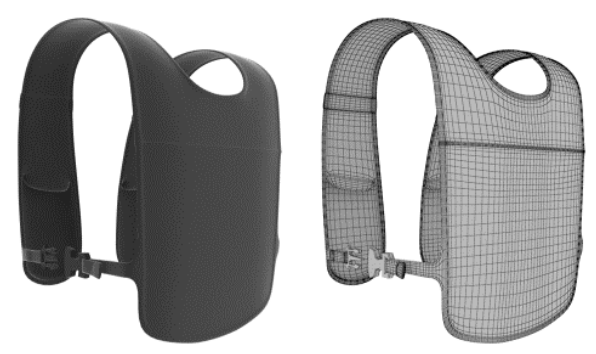

Figure 12. Back of the protective vest.

The revised design of the protective vest is shown below: 


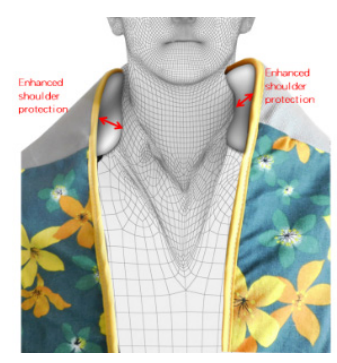

Figure 13. Enhanced shoulder protection.

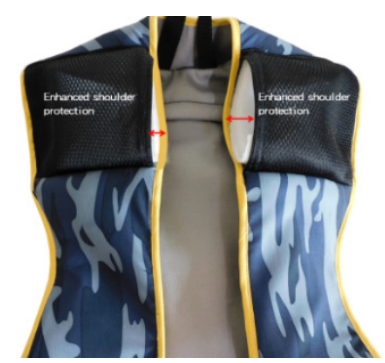

Figure 14. Shoulder pad design on the inside of the protective vest.

Protective vest material design focused on the user's will as the main consideration:

- Denim on the shoulder prevents the car from sliding

- The vest body uses cotton to absorb sweat.

- The inside of the vest is made of functional fabrics that absorb moisture and wick away perspiration.

- The shoulder pad net bag design of the protective gear can freely change the material of the shoulder pad, which is convenient for users to use on different occasions.

Enhanced shoulder protection used 20-mm thick EVA (ethylene-vinyl acetate copo) high-density foam cushion in the shoulder pad.

After the samples of the protective vests in the three colors of gray (see Figure 15a), blue (see Figure 15b) and green (see Figure 15c) were completed, experienced palanquin-carrying personnel were asked to try them on. The testers were asked for their expectations of the protective vests before trying them on. After trying them on, they were asked about their satisfaction with the protective vest. There are three major items:

- Physical experience

- External image

- Function

One hundred questionnaires were analyzed with SPSS. The respondents were people with experience in carrying a palanquin. One hundred questionnaires were sent, and 74 were recovered. The recovery rate was $74 \%$. One of the questionnaires was incomplete and so it was invalid. After excluding one invalid questionnaire, there were 73 valid questionnaires, which could be used as the basis for the conclusion of the study. The distribution period was 18 to 20 February 2020. The questionnaires were sent to Taichung City and Kaohsiung City. The reason is that these two cities are located in central and southern Taiwan, and the religious activities of the people in central and southern Taiwan are more active than those in northern Taiwan. The respondents were of both genders, and the purposeful sampling was adopted. Palanquin carriers' expectations on the advantages of wearing a protective vest. When you wear a protective vest for palanquin carrying, which advantage will you give priority to? Please list priorities for the following seven options:

- A. Comfortable 
- B. Reduce discomfort on shoulder

- C. Team recognition

- D. Good looking

- E. Move smoothly

- F. Remain stable

- G. Easy to put on and take off

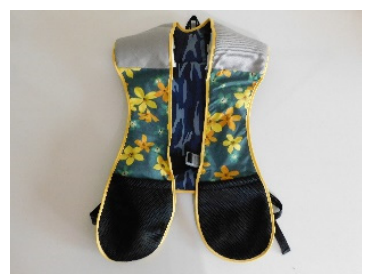

(a) Gray protective vest sample.

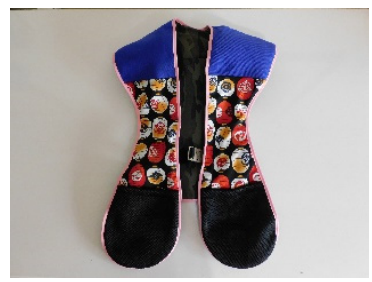

(b) Blue protective vest sample.

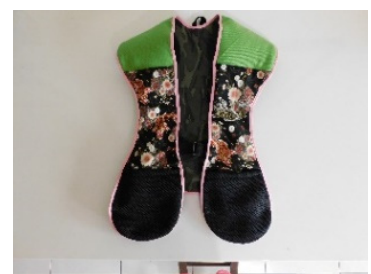

(c)Green protective vest sample.

Figure 15. Protective vest sample with three colors.

Calculate the ranking of values by accumulating points (see Figure 16).

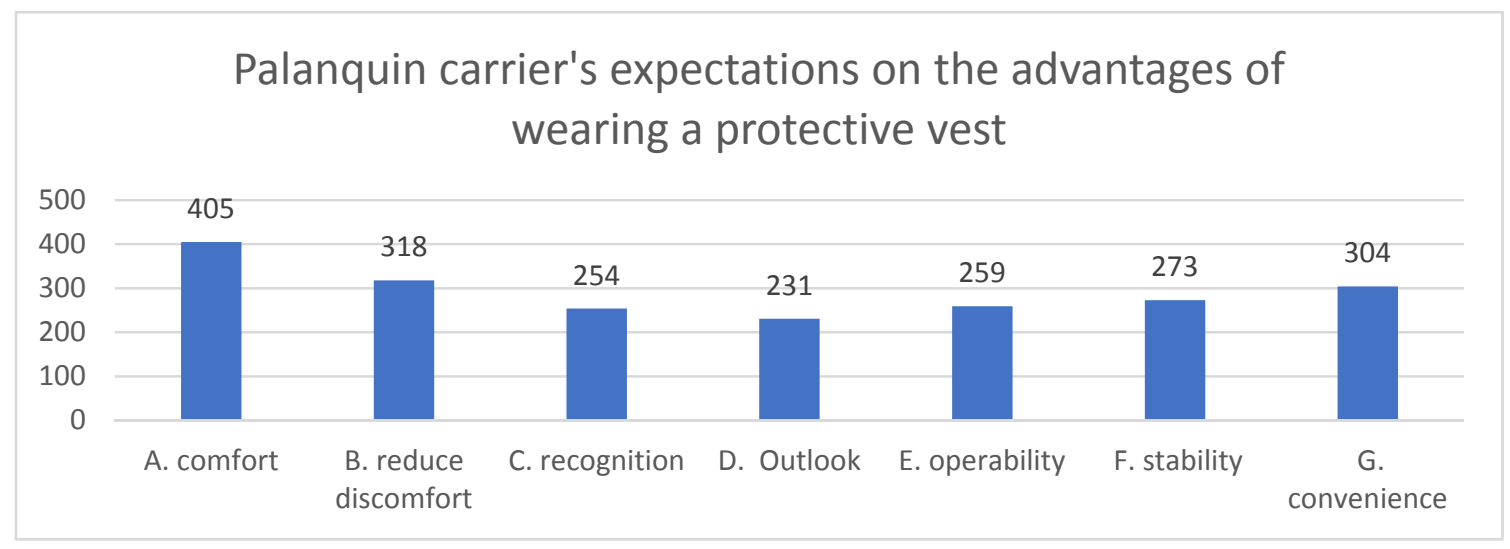

Figure 16. Palanquin carrier's expectations on the advantages of wearing a protective vest.

A KMO (Kaiser-Meyer-Olkin) test was used to determine whether the data are suitable for factor analysis. Three items, such as physical experience, external image, and function, were tested on user satisfaction after using the protective vest. KMO is a measure of the appropriateness of sampling. When the KMO value is larger, it means that there are more common factors among the variables, which is more suitable for factor analysis. According to Kaiser's point of view, KMO $>0.8$ means meritorious, $\mathrm{KMO}>0.7$ means middling, $\mathrm{KMO}>0.6$ means mediocre, and $\mathrm{KMO}<0.5$ means unacceptable (see Table 2).

Table 2. Kaiser-Meyer-Olkin (KMO) test.

\begin{tabular}{ccc}
\hline & Sampling Appropriateness of KMO & $p$ Value \\
\hline Physical experience & 0.655 & $0.000^{*}$ \\
External image & 0.715 & $0.000^{*}$ \\
Function & 0.789 & $0.000^{*}$ \\
\hline
\end{tabular}

${ }^{*} p<0.001$ 
- Reliability analysis of self-perceived variable pretest: When this study performed pretest reliability analysis of herd behavioral variable, the overall Cronbach's $\alpha$ coefficient of the perceptual variable is 0.755 . The overall Cronbach's $\alpha$ coefficient value of self-perception is greater than 0.7 , which shows a good level of reliability.

- Reliability analysis before external image variables: When the reliability analysis before the value cognitive variables was performed in this study, it is shown in the overall Cronbach's $\alpha$ coefficient of the value cognitive variable is 0.78 . Since the overall Cronbach's $\alpha$ coefficient value of the external image is greater than 0.7 , the display scale is used to measure the external image with a sufficiently good level of reliability.

- Reliability analysis before using functional variables: When the reliability analysis before the value recognition variable was performed in this study, it is shown in the overall Cronbach's $\alpha$ coefficient of the value cognitive variable is 0.701 . Because the overall Cronbach's $\alpha$ coefficient value of the use function is greater than 0.7 , it shows that the scale has a good enough level of reliability to measure the use function.

After use, in terms of physical experience, the item with the highest percentage of very satisfied choices is survey on the satisfaction of the comfort of wearing the protective vest, up to $41 \%$ (see Figure 17).

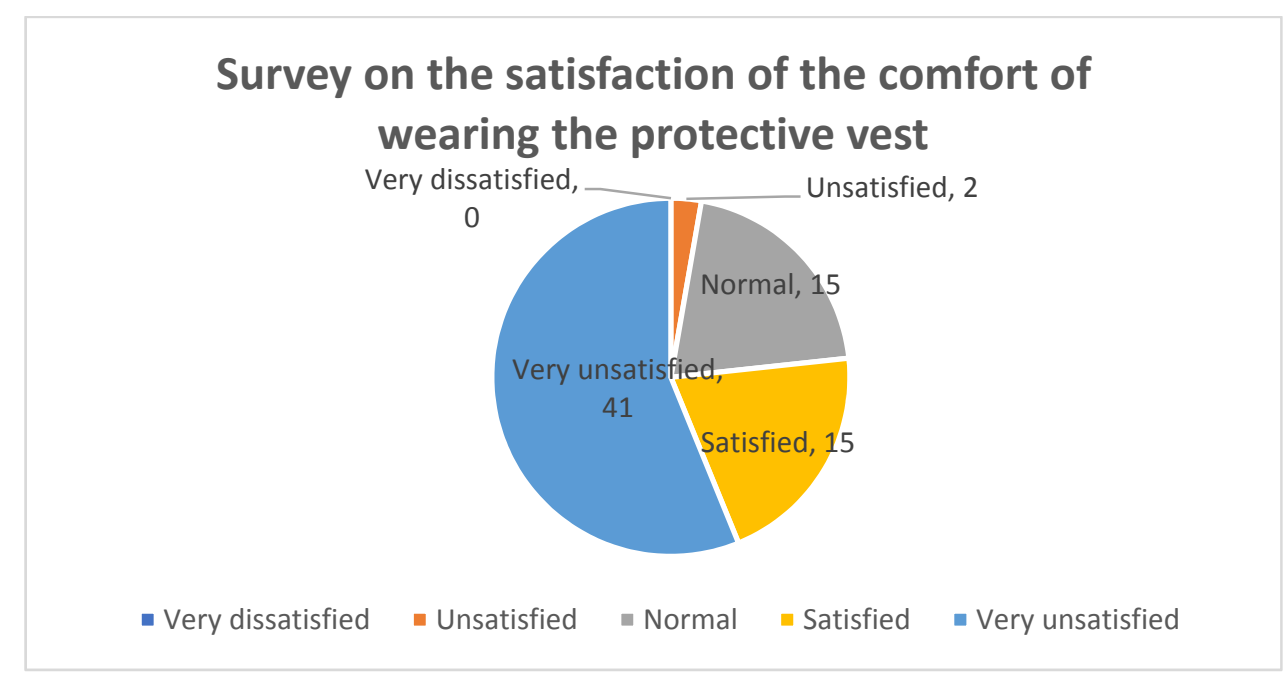

Figure 17. Survey on the satisfaction of the comfort of wearing the protective vest.

After use, as far as external image is concerned, the item with the highest satisfaction is survey on the preference of the temple logo on the protective vest up to $27 \%$ (see Figure 18). 


\section{Survey on the preference of the temple logo on the protective vest}

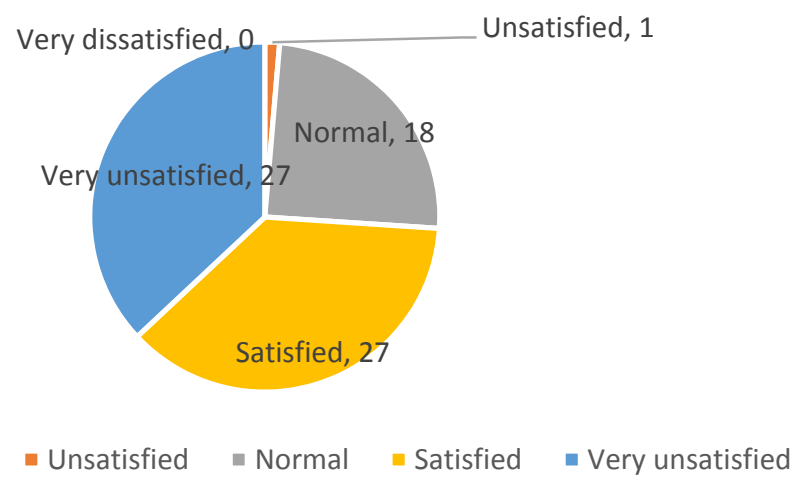

Figure 18. Survey on the preference of the temple logo on the protective vest.

After use, as far as functionality is concerned, the item with the highest satisfaction is survey on the satisfaction of preventing firecracker injuries up to $28 \%$ (see Figure 19).

\section{Survey on the satisfaction of preventing firecrackers from being injured}

Very dissatisfied, 0

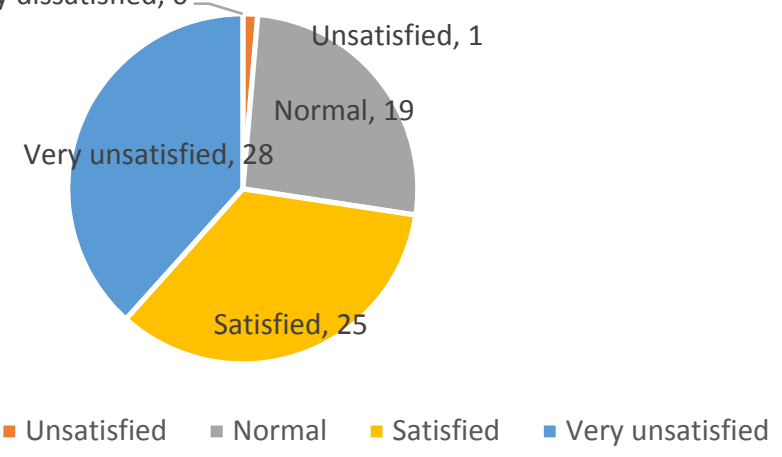

Figure 19. Survey on the satisfaction of preventing firecrackers from being injured.

In summary, after the sample of the protective vest is used, the most satisfactory part of the person carrying the palanquin to the protective vest can provide a reference for the design of the protective vest product in the future. A good design of a palanquin-carrying protective vest should meet the wishes of the palanquin-carrying personnel. The protective vest should be comfortable to wear, with a palace temple logo design on it, and can prevent detours when firing firecrackers are used. It may cause injury to the palanquin operator.

\section{Conclusions}

This design used shoulder protectors to reduce the pain of the palanquin carrier. It is recommended that the palanquin carrier wear a shoulder protective vest with a protector applied to each shoulder to share the weight of the palanquin carried by the shoulder to maintain a good physical condition, so as to facilitate the completion of the event of two days and one night. The design of the palanquin-carrying protective vest avoids the discomfort of the palanquin carriers, so that the next generation will be willing to join the palanquin-carrying team. 
Thinking from the perspective of community design, the research of designing assistive devices for exclusive palanquin carriers for the detour event is only to create an opportunity to meet the team of palanquin carriers. During the contact, we found the palanquin carriers are excited and feel valued. They cannot wait to wear the protective vest which they were involved in designing, and eager to put the protective vest on during the next detour. They look forward to becoming the focus of attention when they are detouring next time. Obviously, the designed protective vest can attract young people. If it can attract young people to join the palanquin carrier team and participate in the detour event, that is how the aging problem is expected to be solved. When young people are enthusiastically engaged in the detour activities, there will be enough young manpower to participate vigorously in the planning of the activity. Then, the crisis of aging and insouciance will sure be lifted. We are sure that the intangible spiritual achievements of community design can be seen very soon. However, we should start the first step, the most important step in fact, with the visible design. At present, the paper can only report on the research results of this first step. The follow-up effect remains to be observed.

Author Contributions: Conceptualization, M.-C.H. and Y.-H.C.; writing-original draft preparation, Y.-H.C.; writing-review and editing, M.-C.H.; supervision, M.-C.H. All authors have read and agreed to the published version of the manuscript.

Funding: This research received no external funding.

Conflicts of Interest: The authors declare no conflict of interest.

\section{References}

1. Yao, B.-H. The Ambrosial Palankeen of Taiwan. Master's Thesis, Graduate College of Architecture and Historic Preservation, Taipei National University of the Arts, Taipei, Taiwan, 2008.

2. World Health Organization. Available online: https:/www.who.int/topics/globalization/en/ (accessed on 29 March 2020).

3. Waters, M. Globalization; Psychology Press: East Sussex, Hove, UK, 2001.

4. Giddens, A. The Consequences of Modernity; Polity University Press: Cambridge, UK, 1990.

5. Friedman, T. The Lexux and the Oliver Tree, 1st ed.; Anchor Books: New York, NY, USA, 2000; Available online: http://www.labeee.ufsc.br/ \{\}luis/egcec/livros/globaliz/TheLexusandtheOliveTree.pdf (accessed on 29 March 2020).

6. Robertson, R. Globalization: Social Theory and Global Culture; Sage: London, UK, 1992.

7. John, T. Globalization and Culture; Polity Press: Cambridge, UK, 2011.

8. Toya, K. Interviewed. "Giving Design a Local Touch: Yamazaki, Ryō and Studio-L”, Nippon.com. Available online: https://www.nippon.com/en/people/e00043/giving-design-a-local-touch-yamazaki-ryo-and-studio-l. html (accessed on 29 March 2020).

9. Liao, C.C. Wanhe Temple History; Wanhe Culture and Education Fund: Taichung, Taiwan, 2004.

(C) 2020 by the authors. Licensee MDPI, Basel, Switzerland. This article is an open access article distributed under the terms and conditions of the Creative Commons Attribution (CC BY) license (http://creativecommons.org/licenses/by/4.0/). 